\title{
Overweight, hypertension and microalbuminuria in urban and rural Bangladeshi schoolchildren
}

\author{
Mohammad Majharul Islam ${ }^{1}$, Md. Benzamin ${ }^{2}$, Ranjit Ranjan Roy ${ }^{1}$, Abdullah Al Mamun ${ }^{1}$ \\ Muhammad Tanvir Ahmmed ${ }^{3}, \mathrm{Md}$. Tariqul Islam ${ }^{4}$, Rezwana Ashraf ${ }^{1}$, \\ Rezaul Karim ${ }^{1}$, Kamal Hossen ${ }^{2}$, Susmita Biswas ${ }^{1}$, Sufia Khatun ${ }^{1}$
}

\begin{abstract}
Background The prevalence of childhood overweight and obesity has increased over the last two decades due to high caloric intake and decreased physical activity which occurred in conjunction with increasing prevalence of hypertension. Microalbuminuria is an early sign of damage to the kidney and cardiovascular system. Hypertensive, overweight children have an increased chance of microalbuminuria.

Objectives To assess the prevalence of overweight, hypertension, and microalbuminuria in urban and rural school going children and contributing risk factors and associations.

Methods This cross-sectional study was done in schoolchildren aged 6 to 16 years, from urban and rural areas, in Bangladesh, from September 2015 untill August 2016. Subjects' weights, heights, and blood pressures (BP) were measured. Overweight and hypertension (HTN) statuses were determined with age-appropriate standardized charts. Subjects were divided into overweight and normoweight groups to evaluate risk factors for overweight such as family history $(\mathrm{F} / \mathrm{H})$ of obesity, $\mathrm{F} / \mathrm{H}$ of $\mathrm{HTN}$, daily physical outdoor activities, and monthly family income by comparative analysis. All overweight children were divided into hypertensive and normotensive groups in order to compare their fasting lipid profiles, urine microalbumin, serum creatinine, and random blood sugar.
\end{abstract}

Results A total of 976 schoolchildren from urban (471, $48.3 \%)$ and rural $(505,51.7 \%)$ areas were included. Overweight was observed in $22.3 \%$ of the urban group and in $8.1 \%$ of the rural group. Hypertension was observed in $24.7 \%$ of overweight children and in $2.5 \%$ of normal weight children. Contributing risk factors for overweight were less physical outdoor activities, F/H of obesity, F/H of HTN, and higher family income. Microalbuminuria and random blood sugar were significantly increased in the overweight with hypertension group compared to the normotensive group.

Conclusion Overweight is a health problem, noted especially in urban areas. Hypertension is also significantly increased in overweight children. Factors like $\mathrm{F} / \mathrm{H}$ of hypertension, obesity, sedentary lifestyle, and higher socioeconomic status are significantly associated with overweight. Microalbu- minuria and increased random blood sugar are also significantly higher observed in hypertensive overweight children compared to normotensive overweight children. [Paediatr Indones. 2019;59:18-26; doi: http://dx.doi.org/10.14238/ pi59.1.2019.18-26 ].

Keywords: microalbuminuria; overweight; hypertension

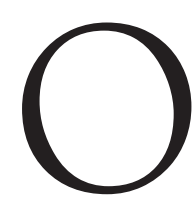
verweight and high blood pressure (HBP) are risk factors directly associated with morbidity and mortality from cardiovascular and renal diseases. ${ }^{1}$ An estimated one-third of pediatric arterial hypertension cases are associated with obesity. ${ }^{2}$ Overweight was associated with increased sympathetic activities, leptin, and angiotensinogen protein expressed in and secreted by adipose tissue. ${ }^{3}$

Hypertension is an important public health problem in different regions of the world because

From the Department of Pediatric Nephrology ${ }^{1}$, Pediatric Gastroenterology and Nutrition ${ }^{2}$, Pediatric Hemato-oncology ${ }^{3}$, and Neonatology ${ }^{4}$, Bangabandhu Sheikh Mujib Medical University (BSMMU), Dhaka, Bangladesh.

Corresponding author: Dr. Md. Benzamin. Department of Paediatric Gastroenterology \& Nutrition, Bangabandhu Sheikh Mujib Medical University, Dhaka, Bangladesh; Phone.+8801719183948 Fax. Email: drmd.benzamin@yahoo.com.

Submitted October 31, 2018. Accepted February 5, 2019. 
of its high prevalence and concomitant risks of cardiovascular and renal diseases. ${ }^{4}$ The prevalence of childhood obesity has increased over the last two decades due to high caloric intake and decreased physical activity. ${ }^{5}$ An increased epidemiological shift from secondary hypertension (most often caused by renal disease) to primary (essential hypertension) is the main cause of hypertension in children. Pediatric primary hypertension has become increasingly common in association with other cardiovascular risk factors, including overweight, insulin resistance and dyslipidemia. ${ }^{6}$

Longitudinal epidemiological studies have demonstrated that body mass index (BMI) above the $85^{\text {th }}$ percentile increases the chances for developing hypertension in adolescents and children. ${ }^{7}$ An analysis of worldwide data estimated that the total population with hypertension in 2000 was 972 million, with 333 million in countries with established market economies and 639 million in economically developing countries. This number was predicted to increase by $60 \%$ ( 1.56 billion) by $2025 .{ }^{8}$ The magnitude of the hypertension burden is predictive of a worldwide cardiovascular disease epidemic. ${ }^{9}$ Increasing prevalence of hypertension occurred in conjunction with an increase in the prevalence of overweight. The prevalence of overweight among children and adolescents increased by $2.5 \%$ from 1990-2010. At the current rate of increase, the worldwide prevalence is expected to exceed $9 \%$ by 2020. ${ }^{10}$ An alarming rise in obesity observed across Europe. ${ }^{11}$ In England, $66 \%$ of men and 55\% of women were deemed either overweight or obese. ${ }^{12}$

In Shangdon, China the prevalences of HBP in overweight and normoweight children were 38.7\% and $11.4 \%$, respectively. ${ }^{13}$ The Bogalusa Heart Study reported that overweight children were 4.5 and 2.4 times likely to have elevated systolic and diastolic blood pressure (SBP, DBP), respectively. ${ }^{14}$ Another study in Chinese children and adolescents showed that obese children had 2.9 times higher risk of developing hypertension compared to normoweight children. ${ }^{15}$ In addition, waist circumference (WC) and BMI were significantly associated with systolic and DBP in adolescents. ${ }^{16}$ An Indian study showed hypertension prevalences of $7.0 \%$ in urban and $2.6 \%$ in rural adolescents as well as significantly increased prevalence of hypertension with increased BMI. ${ }^{17}$
Body mass index was found to be positively related to the risk of high SBP and DBP, with 1.9 times increased risk of high SBP and 1.2 times increased risk of high DBP in those who were either overweight or obese compared to normoweight subjects. ${ }^{18}$

Microalbuminuria is an early sign of damage to the kidney and cardiovascular system. ${ }^{19}$ The prevalence of microalbuminuria was reportedly $10-15 \%$ in the general population, ${ }^{20}$ and $33.2 \%$ in schoolchildren. It was significantly higher in females $(45.3 \%)$, obese subjects $(35.4 \%)$, and those with hypertension (70.6\%). ${ }^{21}$ The prevalences of overweight, obesity, and hypertension were 9.3\%, $8.9 \%$, and $6.1 \%$, respectively, in schoolchildren aged 5-15 years. Obese children had the highest rate of hypertension, with significantly higher systolic and diastolic BP $z$-scores. The estimated glomerular filtration rates (eGFR) were lower in obese children compared to normoweight children, but the difference was not statistically significant. ${ }^{22}$

In our study, we had several aims: (1) to determine the prevalence of microalbuminuria in schoolchildren with overweight-related hypertension, (2) to determine the prevalence of overweight in both urban and rural schoolchildren, (3) to determine the prevalences of overweight by age groups and sex in schoolchildren, (4) to assess for an association between overweight and HTN in schoolchildren, (5) to identify contributing risk factors for overweight such as family history of obesity, HTN, daily physical outdoor activities, and monthly family income, (6) to determine the prevalence of microalbuminuria in overweight urban and rural schoolchildren, (7) to determine the prevalence of microalbuminuria in overweight boys vs. girls, (8) to perform a comparative analysis between overweight children with and without hypertension by lipid profiles, random blood sugar (RBS), serum creatinine, and urinary microalbumin.

\section{Methods}

This cross-sectional descriptive study was done in both rural (Gazaria, Munshigonj) and urban (Narayangonj City) primary and secondary schools in Bangladesh, from September 2015 to August 2016. The inclusion criteria were healthy schoolchildren aged 6 to 16 years. The exclusion criteria were children with 
overweight and hypertension due to secondary causes (renal, endocrine, cardiovascular, or drugs) by history and clinical examination, children who refused to participate, or children outside the age range of 6-16 years.

The sample was collected from the following schools: Agrani Biddaniketon School, Narayangonj (urban); and Daulatpur Bright Preparatory School, Daulat pur, Rasulpur Model Primary School, and Gazaria Pilot High School, Gazaria, Munshiganj (rural), by a convenient purposive sampling method. Urban was defined as area under city corporation or municipality in Bangladesh, while rural was area other than a city corporation or municipality in Bangladesh.

Before collecting data, permission was granted by the schools' headmasters. Written informed consent was signed either by parents or legal guardians. Data were collected by a structured questionnaire that included all variables of interest.

Anthropometric measurements including height and weight were measured following standardized procedures. Weight was measured to the nearest 0.1 $\mathrm{kg}$ with a portable digital bathroom scale. Height was measured to the nearest $0.1 \mathrm{~cm}$ using a stadiometer with the subject barefooted and his/her back against the wall. Body mass index (BMI) was calculated as weight in kilograms divided by the square of height in meters, and categorized as normal weight (BMI between $5^{\text {th }}$ to $85^{\text {th }}$ percentile), underweight $(\mathrm{BMI}<$ $5^{\text {th }}$ percentile), or overweight (BMI $>85^{\text {th }}$ percentile), according to the chart. ${ }^{23}$

Blood pressure was measured by the auscultatory method with an aneroid sphygmomanometer, with the subject's right arm at heart level, using a pediatric cuff of appropriate size at basal state. The cuff should cover at least two-thirds of the arm. Blood pressure was measured 3 times before a hypertensive diagnosis was given. The subject was seated quietly for at least 5 minutes before measurement. Systolic BP was determined in Korotkoff's phase I, whereas diastolic BP was determined in Korotkoff's phase V. The lowest values for SBP and DBP were used in the analyses. Blood pressure was categorised as hypertension (SBP and/or DBP values $>95^{\text {th }}$ percentile) or normotensive (SBP and/or DBP values between $5^{\text {th }}$ and $95^{\text {th }}$ percentile), according to sex, age, and height. ${ }^{24}$

Overweight children underwent further evaluations of daily physical outdoor activities, monthly family income, family history of obesity and hypertension, as well as evidence of renal, endocrine and cardiovascular diseases by history and clinically. We also measured overweight subjects' lipid profile, urine microalbumin, serum creatinine, and RBS (Dimension RXL Max Machine-2, Biochemistry Department, BSMMU, Dhaka and Popular Laboratory and Diagnostic Center, Narayangonj). Microalbuminuria was defined as an increased urine albumin excretion $(30-300$ $\mathrm{mg} / 24 \mathrm{~h}$ ) that is undectable by standard protein dipstick testing. ${ }^{25}$ In this study, urine microalbumin $>20 \mathrm{mg} / \mathrm{L}$ was considered to be microalbuminuria.

The frequency of overweight, normal weight, underweight, and HTN were estimated as percentages in both urban and rural groups. Comparative analysis of normal weight and overweight in urban and rural groups was done by Chi-square test. The percentage of HTN was estimated and comparatively analyzed in the overweight and normoweight groups. Comparative analyses were done between the overweight and normoweight group to assess for possible contributing risk factors for overweight such $\mathrm{F} / \mathrm{H}$ of obesity, $\mathrm{F} / \mathrm{H}$ of HTN, daily physical outdoor activities, and monthly family income. Lastly, the fasting lipid profile, urine microalbumin, serum creatinine, and RBS were compared in overweight children with and without hypertension group.

We used SPSS software version 22 for statistical analyses. For all statistical tests, $\mathrm{P}$ values $<0.05$ were considered to be statistically significant. Continuous variables are presented as mean (SD). Continuous variables were compared by student's unpaired T-test, and categorical variables by Chi-square test. Prior to the commencement of this study, the thesis protocol was approved by the Institutional Review Board of BSMMU, Dhaka.

\section{Results}

Table 1 shows the demographic characteristics of participants. Among them, 471 (48.3\%) were from urban and 505 (51.7\%) were from rural areas. Among urban participants, 257 (54.6\%) were boys and 214 (45.4\%) were girls, similar to the rural distribution of 299 (59.2\%) boys and 206 (40.8\%) girls. Among urban participants, 141 (29.9\%) were aged 6-10 years and 330 
(70.1\%) were 11-16 years; among rural participants, $240(47.6 \%)$ were $6-10$ years and $265(52.4 \%) 11-16$ years, which were significantly different $(\mathrm{P}=0.001)$. The prevalences of overweight were also significantly different, with $105(22.3 \%)$ in urban and $41(8.1 \%)$ in rural children. Likewise, the prevalence of HTN was significantly higher in urban (38 subjects, $8.1 \%$ ) than in rural children (15 subjects, $3.0 \%)$. Overweight with hypertension was seen in $5.7 \%$ and $1.8 \%$, of urban and rural, respectively. Overweight, HTN, and overweight/ HTN combined were all significantly higher in urban than rural subjects $(\mathrm{P}<0.001$ for all).

Table 2 shows the prevalences of overweight among urban and rural boys and girls. Overweight among boys was highest (33.7\%) in the 12-14-year age group, followed by $22 \%, 20.7 \%, 13 \%$, and $10.4 \%$ in the age groups of $10-12$ years, $6-8$ years, $14-16$ years, and $8-10$ years, respectively. For girls, overweight was highest $(29 \%)$ in the 10-12-year age group, followed by $23.2 \%, 18.8 \%, 16.0 \%$, and $13 \%$ in the age groups of $6-8$ years, $12-14$ years, $8-10$ years, and $14-16$ years, respectively. The only significant difference between boy and girls was in the 12-14 year age group, with more overweight boys than overweight

Table 1. Demographic characteristics of participants by location $(\mathrm{n}=976)$

\begin{tabular}{lccc}
\hline Characteristics & $\begin{array}{c}\text { Urban } \\
(\mathrm{n}=471)\end{array}$ & $\begin{array}{c}\text { Rural } \\
(\mathrm{n}=505)\end{array}$ & P value \\
\hline $\begin{array}{l}\text { Sex, } \mathrm{n}(\%) \\
\quad \text { Male }\end{array}$ & $257(54.6)$ & $299(59.2)$ & 0.143 \\
$\quad$ Female & $214(45.4)$ & $206(40.8)$ & \\
Age group, $\mathrm{n}(\%)$ & & & \\
$\quad$-10 years & $141(29.9)$ & $240(47.6)$ & 0.001 \\
$\quad 11-16$ years & $330(70.1)$ & $265(52.4)$ & \\
Overweight, $\mathrm{n}(\%)$ & $105(22.3)$ & $41(8.1)$ & $<0.001$ \\
HTN, n (\%) & $38(8.1)$ & $15(3.0)$ & $<0.001$ \\
Overweight $+\mathrm{HTN}, \mathrm{n}(\%)$ & $27(5.7)$ & $9(1.8)$ & $<0.001$ \\
Chi-square test & & & \\
& & &
\end{tabular}

girls $(\mathrm{P}=0.042)$.

Table 3 shows the frequency of BMI status and the frequency of HTN in urban and rural children by BMI status. Of 471 urban subjects, $22.3 \%$ were overweight, $65.8 \%$ were normal weight, and $11.9 \%$ were underweight. Hypertension was seen in 25.7\% of the overweight and 3.5\% of the normoweight urban subjects. In rural areas, $8.1 \%$ were overweight, $71.5 \%$ normoweight, and $20.4 \%$ underweight; HTN was seen in $21.9 \%$ of the overweight group and $1.6 \%$ of the normoweight group.

Table 4 shows the association between BMI status and BP status. Significantly more overweight subjects were hypertensive $(36 ; 24.7 \%)$ than normoweight subjects $(17 ; 2.5 \%)(\mathrm{P}<0.001)$. Table 5 shows the associations between BMI status and SBP or DBP. SBP and DBP were both significantly higher in overweight than in normoweight children. Table 6 shows the association between monthly family income and BMI status. Overweight was associated with the high income group. The majority of overweight and normoweight subjects were in the 10,000-30,000 $\mathrm{Tk} / \mathrm{mo}$ group. Significantly more normoweight than overweight subjects were in this income
Table 2. Overweight among boys and girls by age grouping

\begin{tabular}{lccc}
\hline Age & $\begin{array}{c}\text { Boys, } n(\%) \\
(n=77)\end{array}$ & $\begin{array}{c}\text { Girls, } n(\%) \\
(n=69)\end{array}$ & P value \\
\hline 6-8 years & $16(20.7)$ & $16(23.2)$ & 0.725 \\
8-10 years & $8(10.4)$ & $11(16)$ & 0.319 \\
10-12 years & $17(22)$ & $20(29)$ & 0.338 \\
12-14 years & $26(33.7)$ & $13(18.8)$ & 0.042 \\
14-16 years & $10(13)$ & $9(13)$ & 0.992 \\
\hline
\end{tabular}

Table 3. BMI category and HTN in urban subjects $(n=471)$

\begin{tabular}{|c|c|c|c|c|}
\hline \multirow[t]{2}{*}{ BMI status } & \multicolumn{2}{|c|}{ Urban } & \multicolumn{2}{|c|}{ Rural } \\
\hline & $\begin{array}{c}\text { Urban, } \\
\mathrm{n} \text { (\% of urban subjects) }\end{array}$ & $\begin{array}{c}\text { HTN and urban, } \\
n(\% \text { of BMl category) }\end{array}$ & $\begin{array}{c}\text { Rural, } \\
\mathrm{n} \text { (\% of rural subjects) }\end{array}$ & $\begin{array}{c}\text { HTN and rural, } \\
\mathrm{n}(\% \text { of BMI category) }\end{array}$ \\
\hline Overweight & $27(25.7)$ & $41(8.1)$ & 9 (21.9) & 105 (22.3) \\
\hline Normoweight & $310(65.8)$ & $11(3.5)$ & $361(71.5)$ & $6(1.6)$ \\
\hline Underweight & 56 (11.9) & $0(0)$ & $103(20.4)$ & $0(0.0)$ \\
\hline
\end{tabular}


category [547 (81.5\%) vs. 65 (44.5\%), respectively; $\mathrm{P}<0.001)]$. However, significantly higher percentages of overweight subjects were in the $30,000-100,000$ $\mathrm{Tk} / \mathrm{mo}$ and $>100,000 \mathrm{Tk} / \mathrm{mo}$ categories $(\mathrm{P}<0.001$ for both).

Table 7 shows the relationship between physical outdoor activities and family history of obesity/ hypertension with BMI status. The frequency of overweight was significantly higher among the children who engaged in physical outdoor activities for $<45$ minutes/day than in the $\geq 45$ minutes/day group $(\mathrm{P}<0.001)$. Significantly higher percentages of overweight children had $\mathrm{F} / \mathrm{H}$ of obesity as well as $\mathrm{F} / \mathrm{H}$ of HTN, compared to the normoweight subjects $(\mathrm{P}<0.001$ for both $)$.
Table 8 shows that the percentages of microalbuminuria in overweight children were not significantly different in urban and rural subjects ( $13.3 \%$ vs. $17.1 \% ; \mathrm{P}=0.824)$. There was no significant difference in microalbuminuria in overweight boys and girls [ $14.2 \%$ vs. $14.4 \%$, respectively; $(\mathrm{P}=0.982)]$.

Table 9 shows the comparison of biochemical parameters (lipid profiles, creatinine, RBS, and urinary microalbumin) in overweight children with HTN and all overweight subjects. Dyslipidemia and high serum creatinine were higher in the hypertensive than the normotensive group, but the difference was not statistically significant. In contrast, urinary microalbumin and RBS level were significantly higher in the hypertensive than the normotensive group $(\mathrm{P}=0.001$ and $\mathrm{P}=0.004$, respectively).

Table 4. Analysis of overweight and HTN

\begin{tabular}{lcccc}
\hline BP status, $n(\%)$ & $\begin{array}{c}\text { Overweight } \\
(n=146)\end{array}$ & $\begin{array}{c}\text { Normoweight } \\
(n=671)\end{array}$ & $\begin{array}{c}\text { Total } \\
(n=817)\end{array}$ & P value \\
\hline Hypertensive & $36(24.7)$ & $17(2.5)$ & $53(6.5)$ & $<0.001$ \\
Normotensive & $110(75.3)$ & $654(97.5)$ & $764(93.5)$ & $<0.001$ \\
\hline
\end{tabular}

Table 5. Association of blood pressures with BMI

\begin{tabular}{lcccc}
\hline \multirow{2}{*}{ BMI } & \multicolumn{2}{c}{ SBP, $\mathrm{mmHg}$} & \multicolumn{2}{c}{ DBP, $\mathrm{mmHg}$} \\
& Mean (SD) & $95 \% \mathrm{Cl}$ & Mean (SD) & $95 \% \mathrm{Cl}$ \\
\hline Overweight $(\mathrm{n}=146)$ & $112.6(14.6)$ & 109.7 to 115.4 & $74.7(9.7)$ & 72.8 to 76.6 \\
Normoweight $(\mathrm{n}=671)$ & $100.5(11.8)$ & 99.2 to 101.8 & $67.1(8.7)$ & 66.1 to 68.1 \\
P value & & $<0.001$ & $<0.001$ \\
Unpaired T-test & & &
\end{tabular}

Table 6. Association of monthly family income with BMI

\begin{tabular}{lccc}
\hline Monthly family income, $\mathrm{n}(\%)$ & Overweight $(\mathrm{n}=146)$ & Normoweight $(\mathrm{n}=671)$ & P value \\
\hline$<10,000 \mathrm{Tk}$ & $13(8.9)$ & $27(4)$ & $<0.054$ \\
$10,000-30,000 \mathrm{Tk}$ & $65(44.5)$ & $547(81.5)$ & $<0.001$ \\
$30,000-100,000 \mathrm{Tk}$ & $46(31.5)$ & $92(13.7)$ & $<0.001$ \\
$>100,000 \mathrm{Tk}$ & $22(15.1)$ & $5(0.7)$ & $<0.001$ \\
\hline
\end{tabular}

Chi-square test, Tk=Bangladesh taka

Table 7. The relationship between some parameters with BMI status

\begin{tabular}{lcccccc}
\hline & \multicolumn{2}{c}{ Parameters, $\mathrm{n}(\%)$} & \multicolumn{3}{c}{ Family history $(\mathrm{F} / \mathrm{H})$} \\
\cline { 2 - 7 } BMI status, $\mathrm{n}(\%)$ & $\begin{array}{c}<5 \mathrm{~min} / \mathrm{day} \\
(\mathrm{n}=160)\end{array}$ & $\begin{array}{c}\geq 45 \mathrm{~min} / \text { day } \\
(\mathrm{n}=657)\end{array}$ & $\mathrm{P}$ value & F/H of obesity & F/H of HTN & P value \\
\hline Overweight & $136(85.0)$ & $10(1.5)$ & $<0.001$ & $71(48.6)$ & $69(47.3)$ & $<0.001$ \\
Nomoweight & $24(15.0)$ & $647(98.5)$ & & $12(1.8)$ & $18(2.7)$ & \\
Chi-square test & & & & & &
\end{tabular}

22 • Paediatr Indones, Vol. 59, No. 1, January 2019 
Mohammad Majharul Islam et al.: Overweight, hypertension, and microalbuminuria in Bangladeshi schoolchildren

Table 8. Microalbuminuria ( $>20 \mathrm{mg} / \mathrm{L}$ ) in correlation with residency and gender

\begin{tabular}{ccc}
\hline & Microalbuminuria & P value \\
\hline Residency, $n(\%)$ & & 0.824 \\
Urban $(n=105)$ & $14(13.3)$ & \\
Rural $(n=41)$ & $7(17.1)$ & \\
Total $(\mathrm{N}=146)$ & $21(14.3)$ & \\
Sex & & \\
Boys $(n=77)$ & $11(14.2)$ & 0.982 \\
Girls $(n=69)$ & $10(14.4)$ & \\
Total $(N=146)$ & $21(14.3)$ & \\
Chi-square test & &
\end{tabular}

found that in England, $66 \%$ of men and 55\% of women were either overweight or obese. ${ }^{12}$ In our study, the largest groups of overweight subjects were the 12-14 years group (33.7\%) of boys, and the 10-12 years group in girls (29\%). Hormonal effect at pubertal ages may contribute. Adrogue et al. found that the prevalence of HTN also increased progressively with age. ${ }^{26}$

In our study, the prevalence of HTN was $8 \%$ in urban and $2.9 \%$ in rural children. In comparison with

Table 9. Comparison of mean lipid profiles, serum creatinine, urinary microalbumin, and RBS in overweight subjects with hypertension and without hypertension

\begin{tabular}{|c|c|c|c|c|c|}
\hline & $\begin{array}{l}\text { Overweight with HTN } \\
\qquad(\mathrm{n}=36)\end{array}$ & $95 \% \mathrm{Cl}$ & $\begin{array}{l}\text { Overweight without HTN } \\
\qquad(\mathrm{n}=110)\end{array}$ & $95 \% \mathrm{Cl}$ & $P$ value \\
\hline Mean cholesterol (SD), mg/dL & $153.8(40.4)$ & 142.6 to 164.9 & $145.5(35.4)$ & 138.2 to 152.8 & 0.198 \\
\hline Mean HDL (SD), mg/dL & $30.1(8.2)$ & 27.8 to 32.3 & $30.1(8.9)$ & 28.3 to 31.9 & 0.994 \\
\hline Mean LDL (SD), mg/dL & $97.1(32.5)$ & 88.1 to 106.1 & $87.7(25.3)$ & 82.5 to 92.9 & 0.053 \\
\hline Mean triglycerides (SD), mg/dL & $151.4(26.3)$ & 144.1 to 158.6 & $145.1(25.1)$ & 139.9 to 150.3 & 0.153 \\
\hline Mean creatinine (SD), mg/dL & $0.67(0.55)$ & 0.55 to 0.78 & $0.64(0.11)$ & 0.61 to 0.67 & 0.749 \\
\hline Mean urinary microalbumin (SD), mg/L & $14.8(12.3)$ & 11.4 to 18.2 & $9.7(5.5)$ & 8.6 to 10.8 & 0.001 \\
\hline Mean RBS (SD), mmol/L & $5.8(1.2)$ & 5.5 to 6.0 & $5.3(0.5)$ & 5.2 to 5.4 & 0.004 \\
\hline
\end{tabular}

Table 10. Comparison of microalbuminuria in overweight children with and without HTN

\begin{tabular}{lccc}
\hline Urinary microalbumin & $\begin{array}{c}\text { Overweight }+\mathrm{HTN}, \mathrm{n}(\%) \\
(\mathrm{n}=36)\end{array}$ & $\begin{array}{c}\text { Overweight without HTN, } \mathrm{n}(\%) \\
(\mathrm{n}=110)\end{array}$ & $\mathrm{P}$ value \\
\hline$>20 \mathrm{mg} / \mathrm{L}$ & $15(41.6)$ & $6(5.4)$ & 0.001 \\
$\leq 20 \mathrm{mg} / \mathrm{L}$ & $21(58.4)$ & $104(94.6)$ & \\
\hline
\end{tabular}

Table 10 shows the comparison of urinary microalbumin in overweight children with and without hypertension. High urinary microalbumin $(>20 \mathrm{mg} / \mathrm{L})$ was observed in hypertensive group $(41.6 \%)$ and it was low in overweight children without hypertension group (5.4\%).

\section{Discussion}

In this cross-sectional study, we examined the prevalence of overweight and its relationship with BP in urban and rural schoolchildren aged 6 to 16 years. Of 976 participants, $15 \%$ were overweight, $22.3 \%$ of urban and $8.1 \%$ of rural children. Aucott et al. found an alarming rise in obesity in the US in the last 15 years, with one-third of the population affected. ${ }^{11}$ Similar trends were seen across Europe. Avenell et al. normoweight children, those who were overweight had significantly higher proportion of high BP. High $\mathrm{BP}$ was found in $24.7 \%$ of the overweight group and $2.5 \%$ of the normoweight group. These results were similar to those of other studies in different countries. Mohan et al. in India found that the prevalence of hypertension was about $7.0 \%$ and $2.6 \%$ amongst urban and rural adolescents, respectively. They also found a significant increase in prevalence of hypertension with an increased BMI. ${ }^{17}$ Muntner et al. found that the childhood obesity epidemic was associated with the increasing prevalence of HTN. ${ }^{27}$ Duzova et al. noted that the prevalences of overweight, obesity, and hypertension were $9.3,8.9$, and $6.1 \%$, respectively, in schoolchildren aged 5-15years. Obese children had the highest rate of hypertension. Systolic and diastolic BP z-scores were significantly higher in obese children. ${ }^{22}$ Din-Dzietham et al. assessed secular high 
BP trends in children and adolescents enrolled in US national surveys, and concluded that the increase was largely attributable to the increase in obesity. ${ }^{28}$ Sorof found that the prevalence of HTN in was 1 to $22 \% .{ }^{29}$ Many of these studies also documented an association between HTN and obesity. In Shangdon, China, Jing Dong et al. found that the prevalence of high BP in obese and normoweight children were $38.7 \%$ and $11.4 \%$, respectively. ${ }^{13}$ The prevalence of HTN seems to be increasing in association with BMI in Canada as well. In our overweight subjects, $\mathrm{F} / \mathrm{H}$ of obesity was present in $48.6 \%$ and $\mathrm{F} / \mathrm{H}$ of $\mathrm{HTN}$ was present in $47.3 \%$. Similarly, Jung et al. found that a family history of HTN was present in approximately $50 \%$ of hypertensive children. ${ }^{30}$ Likewise, Stamler et al. and Longini et al. found that HTN had long been known to cluster within families, possibly due to shared environmental exposures (obesity, salt intake, lifestyle, etc.). ${ }^{31,32}$ We also found that $93.2 \%$ of the overweight group compared to $3.6 \%$ of the normoweight group engaged in $<45$ minutes of daily physical outdoor activities. Pardee et al. found that in obese children, the amount of time spent watching TV was associated with both HTN and the severity of obesity. ${ }^{33}$ Cleroux et al. found that moderate activity was more effective than vigorous activity in reducing SBP. ${ }^{34}$

We analyzed the overweight children in terms of lipid profile, serum creatinine, RBS, and urinary microalbumin between hypertensive and normotensive children. Hypertension was strongly associated with high urinary microalbumin and increased blood glucose level. These conditions may be due to early kidney damage and insulin resistance. Serum creatinine and dyslipidemia were higher in the hypertensive group, but not significantly. Duzova et al. also observed that mean estimated GFR was lower in obese children, but not of statistical significance. No study has shown dyslipidemia in obese children. ${ }^{22}$

In our study, microalbuminuria $(>20 \mathrm{mg} / \mathrm{L})$ was seen in $14.3 \%$ of overweight children overall, with $13.3 \%$ urban and $17 \%$ rural, $14.2 \%$ boys and $14.4 \%$ girls, $5.4 \%$ normotensive, and $41.6 \%$ hypertensive. Okpere et al. reported that the prevalence of microalbuminuria in school children was $33.2 \%$. It was significantly higher in females $(45.3 \%)$, obese subjects $(35.4 \%)$, and those with hypertension (70.6\%). ${ }^{21}$ Mogenson et al. found that the prevalence of microalbuminuria in the general population was

\section{$10-15 \% .20$}

Diercks et al. found that microalbuminuria was an early sign of damage to the kidney and cardiovascular system. ${ }^{19}$ Assadi noted a relationship between left ventricular hypertrophy (LVH) and microalbuminuria in hypertensive subjects, and documented that urinary albumin excretion was increased in children and adolescents with HTN in correlation to LVH. ${ }^{35}$ Nguyen et al. found that microalbuminuria was associated with HTN among overweight adolescents. ${ }^{36}$ Lubrano et al. found that children with prehypertension showed increased prevalence of microalbuminuria and proteinuria, while children with white coat hypertension showed no signs of HTN-related renal damage. ${ }^{37}$

Our study limitations were small sample size, no comparison of lipid profile, blood sugar, urine microalbumin and serum creatinine with normal weight and underweight children due to social and financial constraints, and secondary causes of overweight and HTN was excluded only by history and clinically. We recommend to conduct a larger multicenter study with a large sample size which provide a comparison of all parameters with normal and underweight children.

Overweight is a health problem especially in urban areas. Hypertension is common in overweight children. Factors like family history of hypertension and obesity, sedentary life style, better solvency are linked to overweight. Microalbuminuria and increased random blood sugar are significantly associated with overweight hypertensive children. Overweight children may have hypertension, as well as microalbuminuria, which can cause renal insufficiency in the future.

\section{Conflict of Interest}

None declared.

\section{Funding Acknowledgment}

The authors received no specific grant from any funding agency in the public, commercial, or not-for-profit sectors. 
Mohammad Majharul Islam et al.: Overweight, hypertension, and microalbuminuria in Bangladeshi schoolchildren

\section{References}

1. World Health Organization. Preventing chronic diseases: a vital investment: WHO Global Report. Geneva: WHO; 2005. p. 44.

2. Weiss R, Dziura J, Burgert TS, Tamborlane WV, Taksali SE, Yeckel CW, et al. Obesity and the metabolic syndrome in children and adolescents. N Engl J Med. 2004;350:2362 74.

3. Sharma AM. Is there a rationale for angiotensin blockade in the management of obesity hypertension? Hypertension. 2004;44:12-9.

4. Whelton PK, He J, Muntner P. Prevalence, awareness, treatment and control of hypertension in North America, North Africa and Asia. J Hum Hypertens. 2004;18:545-51.

5. Ogden CL, Troiano RP, Briefel RR, Kuczmarski Rj, Flegal KM Johnson CL. Prevalence of overweight among preschool children in the United States, 1971 through 1994. Pediatrics. 1997;99:E1.

6. Elcarte LR, Villa EI, Sada GJ, Gasco EM, Oyarzabal IM, Sola MA, et al. Prevalence of arterial hypertension, hyperlipidemia and obesity in the infant-child population of Navarra. Association of risk factors. An Esp Pediatr. 1993;38:428-36.

7. Burke V, Beilin LJ, Dunbar D, Kevan M. Associations between blood pressure and overweight defined by new standards for body mass index in childhood. Prev Med. 2004;38:558-64.

8. Kearney PM, Whelton M, Reynolds K, Muntner P, Whelton PK, He J. Global burden of hypertension: analysis of worldwide data. Lancet. 2005;365:217-23.

9. Murray CJL, Lopez AD. Global comparative assessment in the health sector. Geneva: WHO; 1994. p. 21-55.

10. Raj M. Obesity and cardiovascular risk in children and adolescents. Indian J Endocrinol Metab. 2012:16:13-9.

11. Aucott L, Poobalan A, Smith WC, Avenell A, Jung R, Broom J. Effects of weight loss in overweight/obese individuals and long-term hypertension outcomes: a systematic review. Hypertension. 2005;45:1035-41.

12. Avenell A, Broom J, Brown TJ, Poobalan A, Aucott L, Stearns SC, et al. Systematic review of the long-term effects and economic consequences of treatments for obesity and implications for health improvement. Health Technol Assess. 2004;8:iii-iv.

13. Dong J, Guo XL, Lu ZL, Cai XN, Wang HC, Zhang JY, et al. Prevalence of overweight and obesity and their associations with blood pressure among children and adolescents in Shandong, China. BMC Public Health. 2014;14:1080.

14. Freedman DS, Dietz WH, Srinivasan SR, Berenson GS. The relation of overweight to cardiovascular risk factors among children and adolescents: the Bogalusa heart study. Pediatrics. 1999;103:1175-82.

15. Li YP, Yang XG, Zhai FY, Piao JH, Zhao WH, Zhang J, et al. Disease risks of childhood obesity in China. Biomed Environ Sci. 2005;18:401-10.

16. Le, S, Bacha F, Arslanian SA. Waist circumference, blood pressure and lipid components of the metabolic syndrome. J Pediatr. 2006;149:809-16.

17. Mohan B, Kumar N, Aslam N. Rangbulla A, Kumbkarni S, Sood NK, et al. Prevalance of Sustained hypertension and obesity in urban and rural school going children in Ludhiona. Indian Heart J. 2004;56:310-4.

18. Kaur S, Sachdev HPS, Dwivedi SN, Lakshmi R, Kapil U, Sareen N, Association of obesity with hypertension amongst school-age children belonging to lower income group and middle income group in national capital territory of Delhi. Indian J Community Med. 2013;38:175-9.

19. Diercks GF, van Boven AJ, Hillege HL, Janssen WM, Kors JA, de Jong PE, et al. Microalbuminuria is independently associated with ischemic electrocardiographic abnormalities in a large non-diabetic population. The PREVEND Study. Eur Heart J. 2000;21:1922-7.

20. Mogensen CE, Keane WF, Bennett PH, Jerums G, Parving HH, Passa P, et al. Prevention of diabetic renal disease with special reference to microalbuminuria. Lancet. 1995;346:1080-4.

21. Okpere AN, Anochie IC, Eke FU. Prevalence of microalbuminuria among secondary school children. Afr Health Sci. 2012;12:140-7.

22. Duzova A, Yalçınkaya F, Baskin E, Bakkaloglu A, Soylemezoglu O. Prevalence of hypertension and decreased glomerular filtration rate in obese children: results of a population-based field study. Nephrol Dial Transplant. 2013;28:166-71.

23. Kuczmarski RJ, Ogden CL, Grummer-Strawn LM, Flegal KM, Guo SS, Wei R, et al. CDC growth charts: United States. Adv Data. 2000;314:1-27.

24. National High Blood Pressure Education Program Working Group on Hypertension Control in Children and Adolescents. The fourth report on the diagnosis, evaluation and treatment of high blood pressure in children and adolescents. Pediatrics. 2004;114:555-76.

25. Rowe DJ, Dawnay A, Watts GF. Microalbuminuria in diabetic mellitus: review and recommendations for the measurement of albumin in urine. Ann Clin Biochem. 1990;27:297-312.

26. Adrogue HE, Sinaiko AR. Prevalence of hypertension in junior high school-aged children: effect of new recommendations in the 1996 Updated Task Force Report" American journal of hypertension. 2001;14:412-4.

27. Muntner P, He J, Cutler JA, Wildman RP, Whelton PK. Trends 
Mohammad Majharul Islam et al.: Overweight, hypertension, and microalbuminuria in Bangladeshi schoolchildren

in blood pressure among children and adolescents. JAMA. 2004;291:2107-13.

28. Din-Dzietham R, Liu Y, Bielo MV, Shamsa F. High blood pressure trends in children and adolescents in national surveys, 1963 to 2002. Circulation. 2007;116:1488-96.

29. Sorof JM, Lai D, Turner J, Poffenbarger T, Portman RJ. Overweight, ethnicity and the prevalence of hypertension in school-aged children. Pediatrics. 2004;113:475-8.

30. Jung FF, Ingelfinger JR. Hypertension in childhood and adolescence. Pediatr Rev. 1993;14:169-79.

31. Stamler R, Stamler J, Riedlinger WF, Algera G, Roberts RH. Family (parental) history and prevalence of hypertension. Results of a nationwide screening program. JAMA. 1979:241:43-6.

32. Longini IM Jr., Higgins MW, Hinton PC, Moll PP, Keller JB. Environmental and genetic sources of familial aggregation of blood pressure in Tecumseh, Michigan. Am J Epidemiol. 1984;120:131-44.

33. Pardee PE, Norman GJ, Lustig RH, Preud'homme D, Schwimmer JB. Television viewing and hypertension in obese children. Am J Prev Med. 2007;33:439-43.

34. Cleroux J, Feldman RD, Petrella RJ. Lifestyle modifications to prevent and control hypertension. Recommendations on physical exercise training. Canadian Hypertension Society, Canadian Coalition for High Blood Pressure Prevention and Control, Laboratory Centre for Disease Control at Health Canada, Heart and Stroke Foundation of Canada. CMAJ. 1999;160:S21-8.

35. Assadi F. Relation of left ventricular hypertrophy to microalbuminuria and C-reactive protein in children and adolescents with essential hypertension. Paediatr Cardiol. 2008;29:580-4.

36. Nguyen S, McCulloch C, Brakeman P, Portale A, Hsu CY. Being overweight modifies the association between cardiovascular risks factors and micro albuminuria in adolescents. Pediatrics. 2008;121:37-45.

37. Lubrano R, Travasso E, Raggi C, Guido G, Masciangelo R, Elli $\mathrm{M}$. Blood pressure load, proteinuria and renal function in prehypertensive children. Pediatr Nephrol. 2009;24:823-31. 